\title{
Komunikasi Efektif dalam Meningkatkan Literasi Kesehatan Mental
}

\author{
Sarah Bryna Grace, Ade Gandha Kurnia Tandra, Mary \\ London School of Public Relations Jakarta \\ Jl. K.H Mas Mansyur, Kav. 35, Jakarta Pusat \\ sb.grace@live,com, adetandra94@gmail.com, leeyenfen79@gmail.com
}

Masuk tanggal : 16-11-2019, revisi tanggal : 14-08-2020, diterima untuk diterbitkan tanggal : 20-08-2020

\begin{abstract}
This article is the result of a communication study research on effective communication conducted by the Into The Light Indonesia community on improving the mental health literacy of young people in Jabodetabek. Mental health in Indonesia has not received enough attention, unlike physical health, so it is necessary to increase understanding of mental health. Since 2013, the Into The Light Indonesia community has been present as a community of young people working as a center for advocacy, study and education on suicide prevention and working on mental health issues in Indonesia. This study aims to reveal differences in mental health literacy levels between young people in Jabodetabek who participate and those who do not participate in Into The Light Indonesia community's activities, reveal the relationship of effective communication with the delivery of mental health literacy related materials, and to evaluate the communication strategy of Into The Light Indonesia community. For this reason, the research method used is a convergent parallel mixed method, in which a quantitative approach by taking two independent samples $(n=120)$ to fill out a questionnaire to compare the level of mental health literacy and measure the effectiveness of communication carried out, as well as a qualitative approach through interviews to identify and evaluate the activities carried out by the Into The Light Indonesia community. The results of this study indicate that statistically, there is no significant difference between the mental health literacy levels of participants and nonparticipants in the Into The Light Indonesia community activities. However, the results of the study show that effective communication significantly increases the level of mental health literacy. Into The Light participants also showed awareness and interest in finding out more mental health related information. In this study it can also be found that a communication strategy approach is needed by adopting local ways to increase audience awareness and interest, as well as quantitative evaluation with clear measurements to measure the achievement of the communication strategy objectives.
\end{abstract}

Keywords: communication strategy, effective communication, mental health literacy

\begin{abstract}
Abstrak
Artikel ini merupakan hasil penelitian studi komunikasi mengenai komunikasi efektif yang dilakukan oleh komunitas Into The Light Indonesia dalam meningkatkan literasi kesehatan mental anak muda di Jabodetabek. Kesehatan mental di Indonesia masih belum mendapat cukup perhatian layaknya kesehatan fisik, sehingga diperlukan peningkatan pemahaman mengenai kesehatan mental. Sejak tahun 2013, komunitas Into The Light Indonesia hadir sebagai sebuah komunitas orang muda yang bergerak sebagai pusat advokasi, kajian, dan edukasi pencegahan bunuh diri dan berkecimpung pada isu kesehatan mental di Indonesia.
\end{abstract}


Penelitian ini bertujuan untuk mengungkap perbedaan tingkat literasi kesehatan mental antara orang muda di Jabodetabek yang berpartisipasi dengan yang tidak berpartisipasi dalam kegiatan komunitas Into The Light Indonesia, mengungkap hubungan komunikasi efektif dalam penyampaian materi terhadap literasi kesehatan mental, dan mengevaluasi strategi komunikasi komunitas Into The Light Indonesia. Untuk itu, metode penelitian yang digunakan adalah metode campuran paralel konvergen, dimana pendekatan kuantitatif dengan mengambil dua sampel independen $(n=120)$ untuk mengisi kuesioner untuk membandingkan tingkat literasi kesehatan mental dan mengukur efektivitas komunikasi yang dilakukan, serta pendekatan kualitatif melalui wawancara untuk mengidentifikasi serta mengevaluasi kegiatan-kegiatan yang dilakukan komunitas Into The Light Indonesia. Hasil penelitian ini menunjukkan bahwa secara statistik, tidak ada perbedaan yang signifikan antara tingkat literasi kesehatan mental partisipan dan nonpartisipan kegiatan komunitas Into The Light Indonesia. Namun, hasil penelitian menunjukkan bahwa komunikasi efektif meningkatkan tingkat literasi kesehatan mental secara signifikan. Terlihat juga adanya awareness dan interest untuk mencari informasi lebih banyak mengenai kesehatan mental pada partisipan kegiatan Into The Light Indonesia. Dalam penelitian ini juga dapat ditemukan bahwa diperlukan pendekatan strategi komunikasi dengan mengadopsi cara-cara lokal untuk meningkatkan awareness dan minat audience, serta evaluasi kuantitatif dengan measurement yang jelas untuk mengukur ketercapaiannya tujuan strategi komunikasi.

Kata Kunci: komunikasi efektif, literasi kesehatan mental, strategi komunikasi

\section{Pendahuluan}

Perhatian terhadap kesehatan mental cenderung mendapatkan prioritas yang rendah, terutama di negara-negara berkembang seperti India, Ghana, Afrika Selatan, Uganda, dan Zambia (Bird et al., 2011; Thara \& Patel, 2010). Indonesia juga mengalami situasi yang serupa, dimana kesehatan mental mendapatkan prioritas penanganan yang rendah dan belum terintegrasi dalam pelayanan kesehatan primer (Makkasau, 2013; Marchira, 2011). Rendahnya tingkat perhatian serta prioritas penanganan kesehatan mental di Indonesia tidak mencukupi standar yang ditentukan oleh WHO untuk negara berkembang (Marchira, 2011). Hal ini menyebabkan kurangnya sumber daya untuk menangani kesehatan mental, stigma terhadap kesehatan mental yang keliru, dan kasus-kasus terkait dengan kesehatan mental yang tidak dapat ditangani sesuai standar (Afifah et al., 2016; Marchira, 2011; Mawarpury et al., 2017). Sebagai contoh, pada tahun 2015, Badan Pusat Statistik (BPS) mencatat hanya ada 812 kasus bunuh diri yang dilaporkan ke pihak berwajib di seluruh wilayah Indonesia (Di provinsi mana banyak orang bunuh diri?, 2016). Hal ini disebabkan oleh stigma negatif yang lekat di masyarakat akan kasus bunuh diri yang dapat mengakibatkan under-report (Bharadwaj et al., 2017). Penyebab utama dari mayoritas kasus bunuh diri adalah penyakit jiwa, dengan skizofrenia, gangguan bipolar, dan depresi yang menjadi faktor risiko tertinggi (Kahn, n.d.). Data hasil Riset Kesehatan Dasar (Riskesdas) 2013 mengungkapkan adanya peningkatan prevalensi gangguan mental emosional yang (depresi, kecemasan) dari $6 \%$ ke 9,8\% pada tahun 2018, tetapi hanya 9\% dari penderita depresi yang mendapatkan pengobatan medis (Badan Penelitian dan Pengembangan Kesehatan, 2013, 2018). Situasi ini menunjukkan bahwa perlu 
Sarah Bryna Grace, Ade Gandha Kurnia Tandra, Mary: Komunikasi Efektif dalam Meningkatkan Literasi Kesehatan Mental

adanya peningkatan prioritas dan perhatian terhadap kesehatan mental, hingga mencapai tingkat prioritas kesehatan jasmani.

Kesehatan mental telah menjadi prioritas pemimpin-pemimpin negara di dunia dengan memasukkannya ke dalam salah satu dari 17 tujuan pembangunan berkelanjutan atau Sustainable Development Goals (SDGs) yang dicanangkan oleh Perserikatan Bangsa-Bangsa (PBB), WHO juga telah menyusun Mental Health Action Plan 2013-2020 secara komprehensif pada forum World Health Assembly yang ke-66 (World Health Organization, n.d.). Regulator di Indonesia juga telah mengeluarkan aturan mengenai kesehatan mental melalui Undang-Undang Republik Indonesia No. 18 Tahun 2014 tentang Kesehatan Jiwa. Namun sayangnya, perwujudan dari Undang-Undang ini masih belum begitu optimal. Hal ini dibuktikan dengan minimnya tenaga ahli dalam bidang ini. Matta (2016) menulis bahwa Indonesia, dengan penduduk sekitar 250 juta jiwa, baru memiliki sekitar 451 psikolog klinis ( 0,15 per 100.000 penduduk), 773 psikiater $(0,32$ per 100.000 orang), dan perawat jiwa 6.500 orang (2 per 100.000 orang). Bahkan, Direktur Bina Kesehatan Jiwa Kementerian Kesehatan RI juga menyatakan bahwa mayoritas puskesmas di wilayah timur Indonesia belum memiliki psikolog. Ditambah dengan tenaga kesehatan, yang terdiri dari bidan dan perawat yang merupakan ujung tombak dalam pelayanan kesehatan masyarakat, masih memiliki kesadaran dan pengetahuan akan kesehatan mental yang belum memadai (Afifah et al., 2016).

Dari fakta-fakta di atas, dapat disimpulkan bahwa literasi kesehatan mental itu sangat penting. Literasi kesehatan mental ini pertama kali dicetuskan oleh Jorm pada tahun 1997. Pengetahuan dan pemahaman akan penyakit kejiwaan diyakini dapat membantu dalam mendeteksi, manajemen, serta pencegahan dari penyakitpenyakit kejiwaan tersebut (Jorm, 2000). Jorm (2012) kemudian menyempurnakan definisi literasi kesehatan mental dengan memasukkan pengetahuan untuk mencegah gangguan mental, memantau perkembangan gejala gangguan mental, pertolongan mandiri yang efektif untuk gejala gangguan mental ringan hingga moderat serta pemberian pertolongan pertama yang tepat pada orang lain yang mengalami gangguan mental. Meski demikian, Jorm (2012) juga menjelaskan bahwa literasi kesehatan mental tidak mendapatkan perhatian yang sama dengan literasi kesehatan fisik. Penelitian tentang upaya intervensi serta memperbaiki kurangnya literasi kesehatan mental pada masyarakat juga tergolong jarang dan tidak terevaluasi dengan baik (Kelly et al., 2007). Ini berdampak pada kurangnya literasi kesehatan mental masyarakat baik remaja maupun dewasa. Hal ini menyebabkan terhambatnya proses deteksi gejala awal dan aksi penanganan yang tepat pada gangguan kesehatan mental (Kelly et al., 2007). Ini menunjukkan bahwa masih dibutuhkannya upaya-upaya lebih lanjut untuk meningkatkan literasi kesehatan mental.

Canadian Alliance on Mental Illness and Mental Health (CAMIMH, dalam Kutcher et al., 2016) menjelaskan bahwa upaya meningkatkan literasi kesehatan mental adalah berbagai keterampilan sosial dan kognitif yang mendukung promosi kesehatan mental itu sendiri. Di Indonesia, ada beberapa organisasi yang berupaya untuk meningkatkan literasi kesehatan tersebut, yakni Into The Light Indonesia, Get Happy, Komunitas Peduli Skizofrenia Indonesia, Indonesia Mental Healthcare 
Foundation, dan ISMILE4YOU (Fanada, 2017). Meski organisasi-organisasi ini memiliki tujuan yang sama yakni peningkatan literasi kesehatan mental, bagian kesehatan mental yang menjadi fokus dalam setiap organisasi berbeda. Into The Light Indonesia sendiri adalah organisasi berfokus untuk mengurangi stigma di masyarakat terhadap orang yang memiliki pemikiran, pernah mencoba, atau yang meninggal akibat bunuh diri, serta mendorong perilaku pencarian bantuan di masyarakat terkait masalah kesehatan jiwa. Komunitas ini mengadakan berbagai program diskusi publik, pelatihan, kampanye, dan hasil penelitian yang bertujuan untuk mengurangi stigma bunuh diri dan meningkatkan pencarian bantuan (Into The Light Indonesia, n.d.). Meski organisasi-organisasi tersebut telah memiliki niat yang baik, diperlukan adanya perencanaan dan aksi yang tepat agar upaya dari masing-masing organisasi dapat memicu peningkatan literasi kesehatan mental. Salah satu upaya tersebut adalah dengan menciptakan kampanye komunikasi strategis (strategic communication) untuk meningkatkan literasi kesehatan mental (Crawford \& Okigbo, 2014). Kelly et al. (2007) memaparkan mengenai empat kategori intervensi literasi kesehatan mental, yakni kampanye komunitas secara keseluruhan, kampanye komunitas yang ditargetkan untuk anak muda, intervensi dan pengajaran di sekolah-sekolah, dan program pelatihan individu.

Komunikasi strategis (strategic communication) adalah komunikasi yang terencana yang dilakukan oleh suatu organisasi untuk mencapai tujuannya, yang meliputi tetapi tidak terbatas pada membangun pemahaman dan dukungan dari target audience (Hallahan et al., 2007; Smith, 2017). Sifat dari komunikasi strategis adalah persuasif dan informatif. Komunikasi strategis juga dilakukan tidak hanya oleh perusahaan dan korporasi, tetapi juga gerakan sosial, aktivis, dan tujuan nonprofit (Hallahan et al., 2007). Komunikasi strategis dapat diaplikasikan dalam berbagai bidang dan tujuan, seperti manajemen, periklanan, penjualan, relasi publik, sosialisasi program pemerintahan, promosi dan branding destinasi wisata, serta berbagai kampanye kesehatan (Astuti et al., 2016; Hallahan et al., 2007; Tunggala \& Saadjad, 2019).

Smith (2017) menjelaskan cara merencanakan kampanye melalui Nine Steps of Strategic Public Relations. Model ini diyakini logis dan dapat dengan mudah diikuti. Langkah-langkahnya dibagi menjadi empat fase, yakni: (1) formative research, menganalisis situasi, organisasi, dan publiknya; (2) strategy, menentukan tujuan dan objektif, menyusun strategi, dan menggunakan komunikasi efektif; (3) tactics, memilih taktik komunikasi serta mengimplementasikan strategic plan; dan (4) evaluative research, mengevaluasi strategic plan yang telah dijalankan. Komunikasi efektif, sebagaimana dikemukakan oleh Smith (2017), merupakan salah satu bagian dari strategy dalam Nine Steps of Strategic Public Relations. Salah satu dasar strategi komunikasi efektif diletakkan oleh Aristoteles yang memaparkan tiga pilar dari retorika-seni komunikasi persuasif-yang menjadi landasan dari komunikasi persuasif hingga saat ini, yakni ethos, logos, dan pathos (Larson, 2010). Ethos berbicara mengenai komunikasi efektif yang berdasarkan karakter komunikator yang meyakinkan. Logos berbicara mengenai daya tarik rasional dari pesan yang disampaikan. Sedangkan pathos berbicara mengenai komunikasi efektif yang melibatkan emosi dan perasaan dalam penyampaian pesan (Smith, 2017). Agar komunikasi efektif dapat terjadi, kedua 
Sarah Bryna Grace, Ade Gandha Kurnia Tandra, Mary: Komunikasi Efektif dalam Meningkatkan Literasi Kesehatan Mental

pihak, baik pengirim maupun penerima pesan harus ikut serta secara aktif untuk mendengarkan (Ennis et al., 2013). Ennis et al. juga menambahkan bahwa komunikasi efektif dapat mengembangkan serta membangun relasi yang lebih kuat. Penelitian menunjukkan bahwa komunikasi efektif dapat meningkatkan tingkat reaksi serta level dari efisiensi menjadi lebih baik (Ereh \& Beshel, 2011, dalam Ennis et al., 2013).

Ada beberapa penelitian terdahulu yang membahas tentang literasi kesehatan mental, yang menjadi dasar sekaligus menunjukkan perbedaan dan keunikan studi ini. Salah satunya berasal dari Kelly et al. (2007) yang menjelaskan mengenai strategi literasi kesehatan mental dalam membantu intervensi awal dalam penanganan gangguan kejiwaan. Kelly et al. melakukan tinjauan pustaka dari studistudi berkenaan dengan mental health literacy dan menjabarkan empat kategori intervensi literasi kesehatan mental, yakni kampanye komunitas secara keseluruhan, kampanye komunitas yang ditargetkan untuk anak muda, intervensi dan pengajaran di sekolah-sekolah, dan program pelatihan individu. Dalam artikel ini, Kelly et al. juga merangkum sejumlah upaya-upaya intervensi literasi kesehatan mental yang telah dilakukan serta mengelompokkannya sesuai keempat kategori tersebut.

Penelitian selanjutnya dilakukan oleh Livingston et al. (2013), yang memaparkan tentang studi efektivitas kampanye In One Voice di media sosial pada 24 Januari 2012 sampai 19 Maret 2012, dalam meningkatkan awareness kesehatan mental dan meningkatkan perilaku remaja serta dewasa muda terhadap isu-isu kesehatan mental. Kampanye ini diunggah pada media sosial dalam bentuk video public service announcement berdurasi dua menit, yang menampilkan atlet hoki dari tim Vancouver Canucks, Kanada.

Penelitian berikutnya dilakukan oleh O'Connor dan Casey (2015), yang menjelaskan tentang tahapan pengembangan Mental Health Literacy Scale (MHLS), sebuah ukuran berbasis skala untuk mengukur tingkat literasi kesehatan mental. O'Connor dan Casey meyakini bahwa cara ukur yang umum digunakan, Vignette Interview, masih terbatas: tidak dapat mewakili seluruh karakteristik literasi kesehatan mental, tidak memiliki sistem skor berbasis skala, dan prosesnya pengukuran yang memakan waktu lama. Pengembangan MHLS ini diharapkan bisa menyediakan sebuah ukuran kuat yang juga hemat waktu.

Selanjutnya penelitian terdahulu yang berkaitan dengan komunikasi efektif di ranah medis dilakukan oleh Fallowfield dan Jenkins (1999), yang membahas mengenai beberapa masalah yang memengaruhi komunikasi dalam onkologi yang akhirnya memengaruhi perawatan pasien. Fallowfield dan Jenkins mengungkapkan komunikasi yang tidak memadai dapat menyebabkan banyak kesulitan bagi pasien dan keluarganya, yang sering kali menginginkan lebih banyak informasi daripada yang biasanya diberikan. Kurangnya komunikasi yang efektif antara spesialis dan departemen juga dapat menyebabkan kebingungan dan hilangnya kepercayaan di antara tim. Komunikasi yang efektif selama konsultasi dapat menentukan keakuratan dan kelengkapan data yang dikumpulkan.

Penelitian ini bertujuan untuk mengungkap perbedaan tingkat literasi kesehatan mental antara orang muda di Jabodetabek yang berpartisipasi dengan yang tidak berpartisipasi dalam kegiatan komunitas Into The Light Indonesia, 
mengungkap hubungan komunikasi efektif dalam penyampaian materi terhadap literasi kesehatan mental, dan mengevaluasi strategi komunikasi komunitas Into The Light Indonesia. Hipotesis komparatif dari penelitian ini adalah terdapat perbedaan tingkat literasi kesehatan mental antara partisipan dan nonpartisipan kegiatan komunitas Into The Light Indonesia, dengan $\mathrm{H}_{0}$ : tidak ada perbedaan dan $\mathrm{H}_{\mathrm{a}}$ : terdapat perbedaan. Hipotesis asosiatif dari penelitian ini adalah terdapat hubungan yang positif dan signifikan antara komunikasi efektif komunitas Into The Light Indonesia dan tingkat literasi kesehatan mental orang muda di Jabodetabek, dengan $\mathrm{H}_{0}$ : tidak ada hubungan dan $\mathrm{H}_{a}$ : ada hubungan. Selanjutnya, penelitian ini juga bertujuan untuk mengungkap strategi Into The Light Indonesia dalam meningkatkan literasi kesehatan mental di kalangan anak muda di Jabodetabek. Penelitian ini diharapkan dapat menjadi landasan untuk meningkatkan efektivitas komunikasi yang dilakukan oleh komunitas-komunitas yang peduli akan kesehatan mental.

\section{Metode Penelitian}

Penelitian ini dibuat dengan metode campuran paralel konvergen, di mana peneliti mengumpulkan baik data kualitatif maupun kuantitatif, menganalisis datadata tersebut secara terpisah dan kemudian mengaitkan hasil analisis data-data tersebut (Creswell, 2014). Dalam penelitian ini, pendekatan kuantitatif dengan rancangan kausal komparatif akan dilakukan untuk membandingkan tingkat literasi kesehatan mental antara partisipan dan nonpartisipan kegiatan komunitas Into The Light Indonesia serta menghubungkannya dengan komunikasi efektif yang dilakukan oleh komunitas Into The Light Indonesia. Kemudian, pendekatan kualitatif akan digunakan untuk menganalisis dan mendalami strategi-strategi komunikasi yang digunakan oleh komunitas Into The Light Indonesia untuk meningkatkan literasi kesehatan mental orang muda di Jabodetabek. Penelitian ini akan menggunakan dua teknik pengumpulan data primer, yakni sampling kuantitatif akan diambil menggunakan survei, melalui pembagian kuesioner, serta melalui wawancara untuk sampling kualitatif.

Populasi dalam penelitian ini adalah seluruh penduduk dalam kelompok usia 16 hingga 30 tahun di Jabodetabek, yang merupakan target audience dan lokasi kegiatan-kegiatan dari komunitas Into The Light Indonesia (Into The Light Indonesia, n.d.). Pengambilan sampel yang dilakukan untuk penelitian ini adalah melalui purposive sampling, yaitu pengambilan sampel dengan menetapkan kriteria khusus (Gunter, 2002) untuk mengambil data partisipan kegiatan Into The Light Indonesia. Dalam penelitian ini, kriteria umum yang ditetapkan untuk sampling responden dengan kelompok nonpartisipan adalah: (a) berumur 15-29 tahun; (b) berdomisili di area Jabodetabek; dan (c) tidak pernah mengikuti kegiatan yang diselenggarakan oleh komunitas Into The Light Indonesia sendiri ataupun yang bekerja sama dengan lembaga lain. Sedangkan kriteria untuk sampling kelompok intervensi/partisipan adalah peserta kegiatan seminar Kenali Aku di Puskesmas Kecamatan Johar Baru atau seminar Transformation 2019 di PKN STAN, Bintaro. Setelah dikalkulasi secara otomatis menggunakan program $\mathrm{G}^{*}$ Power 3, maka total 
Sarah Bryna Grace, Ade Gandha Kurnia Tandra, Mary: Komunikasi Efektif dalam Meningkatkan Literasi Kesehatan Mental

ukuran sampel minimum yang dibutuhkan adalah sebesar 120 sampel, di mana masing-masing kelompok independen memiliki ukuran sampel sebesar 60 sampel.

Sebanyak 31 orang laki-laki dan 89 orang perempuan berpartisipasi dalam survei literasi kesehatan mental: 19 orang laki-laki dan 41 orang perempuan yang tidak pernah berpartisipasi (NP) dalam kegiatan Into The Light Indonesia, 12 orang laki-laki dan 48 orang perempuan yang berpartisipasi (P) dalam kegiatan Into The Light Indonesia. Penyebaran domisili sampel didominasi oleh Tangerang untuk partisipan kegiatan Into The Light Indonesia, sedangkan untuk nonpartisipan didominasi oleh orang-orang yang berdomisili di Jakarta.

Unit analisis penelitian ini adalah komunitas Into The Light Indonesia, di mana data kualitatif dari penelitian ini diperoleh dari wawancara dengan pendiri komunitas Into The Light Indonesia, Benny Prawira Siauw, sebagai narasumber pertama. Narasumber kedua yakni Nico Wattimena, seorang independent strategic communication consultant, guna mengevaluasi strategi komunikasi yang dicanangkan oleh Into The Light Indonesia.

Dua variabel yang dipakai dalam penelitian ini yaitu, komunikasi efektif komunitas Into The Light Indonesia sebagai variabel bebas (X) dan literasi kesehatan mental sebagai variabel terikat (Y). Mengacu kepada Smith (2017), variabel komunikasi efektif komunitas terbagi menjadi sembilan dimensi yang masing-masing dapat memiliki lebih dari satu indikator seperti bias dilihat pada Tabel 1. Sementara untuk operasionalisasi variabel literasi kesehatan mental penulis mengacu kepada Jorm (2000) serta O’Connor \& Casey (2015). Pemahaman kesehatan mental terdiri dari enam indikator seperti pada Tabel 1 di bawah ini. Kuantifikasi masing-masing indikator untuk dua variabel utama tersebut menggunakan skala Likert (Hair et al., 2019).

Tabel 1. Tabel Operasional Variabel

\begin{tabular}{lcll}
\hline Variabel Utama & Dimensi & \multicolumn{1}{c}{ Indikator } & Code \\
\hline & & $\begin{array}{l}\text { Expertise: Komunikator } \\
\text { sangat memahami pesan } \\
\text { yang disampaikan }\end{array}$ & $\mathrm{X}_{1.1}$ \\
& & \\
& & $\begin{array}{l}\text { Status: Komunikator } \\
\text { memiliki posisi sosial yang } \\
\text { baik. }\end{array}$ & $\mathrm{X}_{1.2}$ \\
& Ethos-Credibility & $\begin{array}{l}\text { Competence: Komunikator } \\
\text { dapat dengan tenang dan } \\
\text { jelas dalam menyampaikan } \\
\text { (Smith, 2005) }\end{array}$ & $\mathrm{X}_{1.3}$ \\
& & $\begin{array}{l}\text { Honesty: Komunikator } \\
\text { memberikan informasi } \\
\text { penuh dan akurat. }\end{array}$ & $\mathrm{X}_{1.4}$ \\
& & $\begin{array}{l}\text { Familiarity: Komunikan } \\
\text { mengenal komunikator. }\end{array}$ & $\mathrm{X}_{2.1}$ \\
\cline { 2 - 4 } & Ethos-Charisma & & \\
& &
\end{tabular}


Likability: Komunikator merupakan sosok yang $\quad \mathrm{X}_{2.2}$ netral.

Similarity: Terdapat

kesamaan antara komunikator dan $\mathrm{X}_{2.3}$ komunikan.

Attractiveness:

Komunikator memiliki $\quad \mathrm{X}_{2.4}$ penampilan yang menarik.

\begin{tabular}{|c|c|c|}
\hline Logos-Proposition & $\begin{array}{l}\text { Pesan yang disampaikan } \\
\text { memiliki satu proposisi dan } \\
\text { tidak membingungkan }\end{array}$ & $\mathrm{X}_{3.1}$ \\
\hline \multirow{5}{*}{$\begin{array}{l}\text { Logos-Verbal } \\
\text { Evidence }\end{array}$} & $\begin{array}{l}\text { Analogies: Komunikator } \\
\text { menggunakan analogi yang } \\
\text { familier dalam penyampaian } \\
\text { pesan. }\end{array}$ & $\mathrm{X}_{4.1}$ \\
\hline & $\begin{array}{l}\text { Comparisons: Komunikator } \\
\text { membandingkan pesan } \\
\text { dengan sebuah situasi yang } \\
\text { bisa dipahami komunikan. }\end{array}$ & $\mathrm{X}_{4.2}$ \\
\hline & $\begin{array}{l}\text { Examples: Komunikator } \\
\text { memberikan contoh- } \\
\text { contoh/ilustrasi yang } \\
\text { relevan. }\end{array}$ & $\mathrm{X}_{4.3}$ \\
\hline & $\begin{array}{l}\text { Statistics: Komunikator } \\
\text { menggunakan data statistik } \\
\text { untuk mendukung pesan. }\end{array}$ & $\mathrm{X}_{4.4}$ \\
\hline & $\begin{array}{l}\text { Testimonies \& } \\
\text { Endorsements: Pesan } \\
\text { didukung oleh komentar dan } \\
\text { ulasan dari pihak lain. }\end{array}$ & $\mathrm{X}_{4.5}$ \\
\hline $\begin{array}{l}\text { Logos-Visual } \\
\text { Supporting } \\
\text { Evidence }\end{array}$ & $\begin{array}{l}\text { Komunikator menggunakan } \\
\text { presentasi visual (grafik, } \\
\text { foto, dan bagan) yang } \\
\text { menarik. }\end{array}$ & $\mathrm{X}_{5.1}$ \\
\hline $\begin{array}{l}\text { Logos-Avoiding } \\
\text { Errors of Logic }\end{array}$ & $\begin{array}{l}\text { Komunikator menghindari } \\
\text { asumsi-asumsi yang salah } \\
\text { dan kesimpulan yang tidak } \\
\text { terjamin. }\end{array}$ & $\mathrm{X}_{6.1}$ \\
\hline
\end{tabular}


Sarah Bryna Grace, Ade Gandha Kurnia Tandra, Mary: Komunikasi Efektif dalam Meningkatkan Literasi Kesehatan Mental

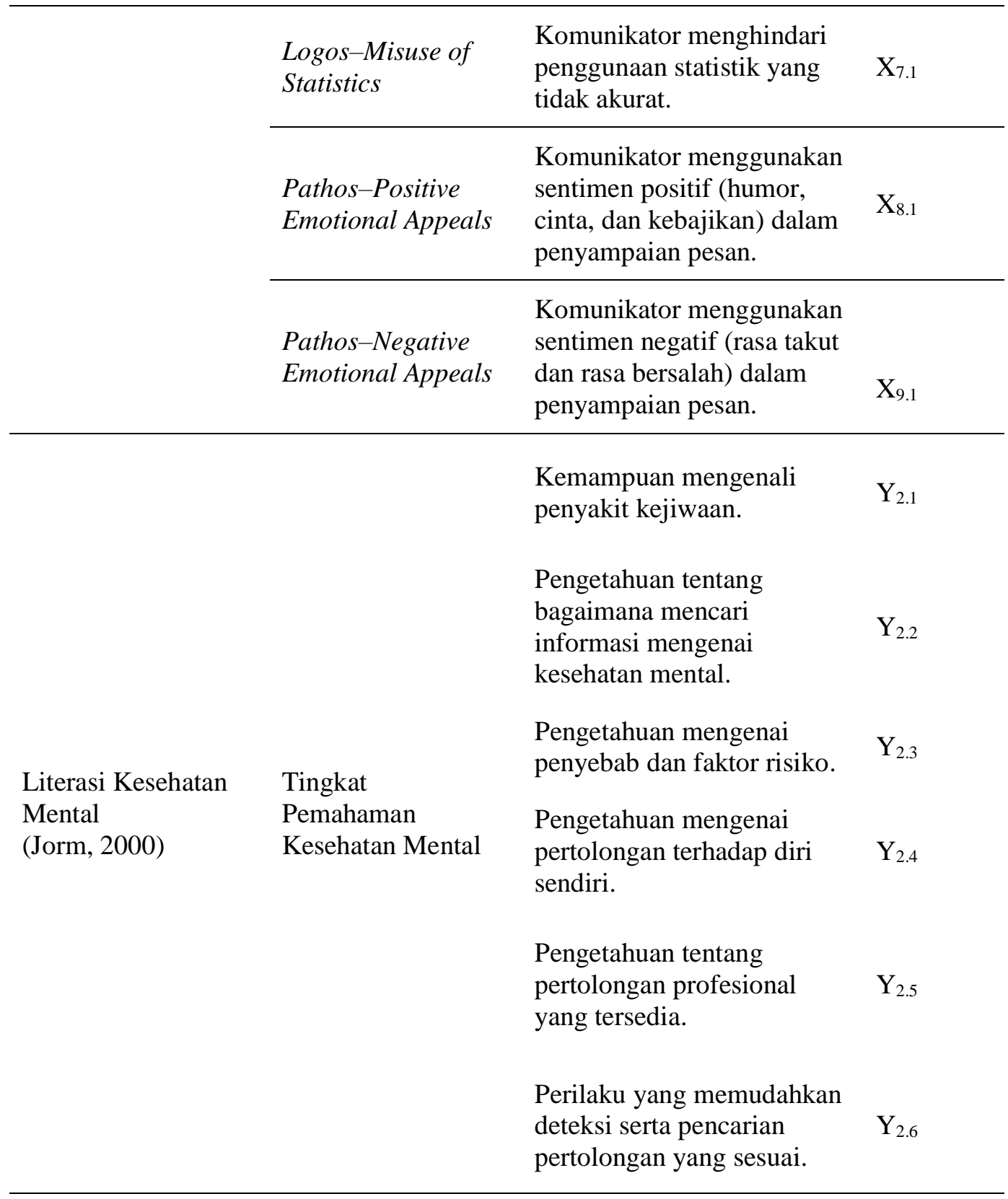

Lembar kuesioner yang dibagikan memiliki pertanyaan sejumlah 19 butir pertanyaan ordinal untuk mengukur tingkat literasi kesehatan mental. Masingmasing pertanyaan dinilai dengan skor 1 sampai 4, sehingga skor total minimal 19 dan maksimal 76, sebagai ukuran untuk membandingkan tingkat literasi kesehatan mental antara partisipan dan nonpartisipan. Komparasi ini akan dianalisis dengan uji analisis independen $t$-test (Creswell, 2014). Bagian kedua dari lembar kuesioner adalah 30 pertanyaan ordinal untuk mengungkap korelasi komunikasi efektif komunitas Into The Light Indonesia terhadap tingkat literasi kesehatan mental. Untuk menguji hipotesis asosiatif antara komunikasi efektif komunitas (variabel bebas) Into The Light Indonesia terhadap tingkat literasi kesehatan mental (variabel terikat), digunakan uji korelasi product moment dari Pearson (Sugiyono, 2015). 
Selanjutnya bagian kualitatif dari penelitian ini memiliki fokus penelitian mengenai strategic communication oleh komunitas Into The Light Indonesia yang terdiri dari empat elemen dalam Nine Steps of Strategic Public Relations yang mengacu kepada Smith (2017). Elemen pertama adalah formative research, di mana peneliti melakukan analisis untuk melihat bagaimana Into The Light memahami tiga aspek situasi yaitu: situasi kesehatan mental masyarakat di Indonesia; memahami lingkungan internal, persepsi publik terhadap komunitas, dan lingkungan eksternalnya; serta memahami target audience yang dituju. Elemen kedua adalah strategy yang terdiri dari: apa visi dan misi Into The Light yang mencerminkan tujuan komunitas; bagaimana Into The Light Indonesia membuat perencanaan sesuai dengan tujuan komunitas dan bagaimana komunitas menentukan pembicara dan pesan yang dapat dikomunikasikan dengan efektif. Elemen ketiga adalah tactics, yang melingkupi bagaimana Into The Light Indonesia menetapkan taktik guna mewujudkan tujuan komunitas dan bagaimana komunitas ini mewujudkan rencana-rencana dalam kegiatan nyata. Elemen yang menjadi fokus terakhir adalah evaluation research yaitu bagaimana Into The Light Indonesia melakukan evaluasi setelah setiap kegiatan.

\section{Hasil Penemuan dan Diskusi}

Dari proses pengumpulan data, diketahui bahwa nilai terendah yang didapat oleh responden adalah 44, sedangkan skor tertinggi adalah 73. Grafik di bawah ini menggambarkan bahwa kecenderungan responden, baik partisipan dan nonpartisipan, meraih tingkat literasi kesehatan mental di atas 50\%. Namun hanya sedikit dari responden yang mendapat nilai di atas $75 \%$.

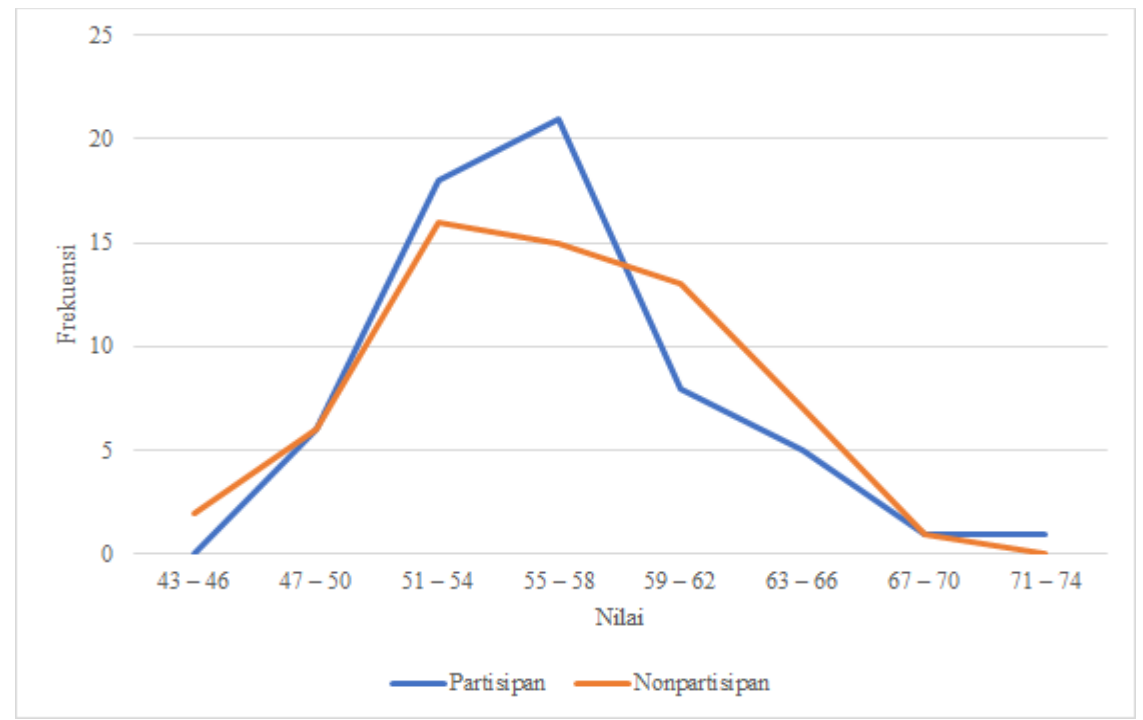

Gambar 1: Grafik Distribusi Frekuensi

Lebih jauh, untuk membandingkan tingkat literasi kesehatan mental lebih akurat, hasil uji independen $t$-test pada tabel di bawah ini menunjukkan bahwa tidak ada perbedaan yang bermakna antara tingkat literasi kesehatan mental partisipan 
Sarah Bryna Grace, Ade Gandha Kurnia Tandra, Mary: Komunikasi Efektif dalam Meningkatkan Literasi Kesehatan Mental

maupun non partisipan. Hal ini ditunjukkan oleh rerata kelompok partisipan yang sedikit lebih rendah dibandingkan dengan kelompok nonpartisipan dan nilai Sig. (2-tailed) adalah 0,930, di mana nilai ini lebih besar dari 0,05.

Tabel 3. Hasil Uji Independent Samples Test

\begin{tabular}{|c|c|c|c|c|c|c|}
\hline \multicolumn{7}{|c|}{ t-test for Equality of Means } \\
\hline \multirow[t]{2}{*}{$t$} & \multirow[t]{2}{*}{ df } & \multirow[t]{2}{*}{$\begin{array}{l}\text { Sig. }(2- \\
\text { tailed })\end{array}$} & \multirow[t]{2}{*}{$\begin{array}{c}\text { Mean } \\
\text { Difference }\end{array}$} & \multirow[t]{2}{*}{$\begin{array}{l}\text { Std. Error } \\
\text { Difference }\end{array}$} & \multicolumn{2}{|c|}{$\begin{array}{l}\text { 95\% Confidence } \\
\text { Interval of the } \\
\text { Difference }\end{array}$} \\
\hline & & & & & Lower & Upper \\
\hline,- 088 & 118 & 930 &,- 083 & 950 & $-1,964$ & 1,797 \\
\hline,- 088 & 117,846 & 930 &,- 083 & 950 & $-1,964$ & 1,797 \\
\hline
\end{tabular}

Dapat diasumsikan bahwa tidak adanya perbedaan tingkat literasi kesehatan mental antara partisipan dan nonpartisipan diakibatkan oleh paparan informasi mengenai kesehatan mental yang cenderung baru. Berhubung partisipan kegiatan ini baru menghadiri kegiatan komunitas Into The Light Indonesia sekali saja. Hal ini menunjukkan bahwa literasi kesehatan mental tidak dapat ditingkatkan secara instan melalui seminar singkat. Namun begitu, kegiatan-kegiatan yang dilakukan oleh komunitas ini dipercaya dapat meningkatkan awareness.

Bagian kedua dari kuesioner kemudian mengukur tingkat komunikasi efektif dalam kegiatan komunitas Into The Light Indonesia, untuk mengungkap hubungan antara komunikasi efektif dan tingkat literasi kesehatan mental. Hasil uji korelasi product moment dari Pearson pada tabel di bawah ini menunjukkan bahwa korelasi koefisien yang diperoleh sebesar 0,513 . Nilai positif dari korelasi koefisien tersebut menunjukkan bahwa apabila variabel komunikasi efektif meningkat, maka variabel literasi kesehatan mental turut naik. Menurut Sujarweni (2016), korelasi yang berada dalam rentang nilai 0,41 hingga 0,70 dapat diinterpretasikan bahwa terdapat hubungan kuat antara kedua variabel.

Tabel 4. Hasil Uji Korelasi Product Moment

\begin{tabular}{|c|c|c|c|}
\hline & & $\begin{array}{c}\text { Literasi Kesehatan } \\
\text { Mental }\end{array}$ & $\begin{array}{c}\text { Komunikasi } \\
\text { Efektif }\end{array}$ \\
\hline \multirow{3}{*}{$\begin{array}{c}\text { Literasi Kesehatan } \\
\text { Mental }\end{array}$} & $\begin{array}{l}\text { Pearson } \\
\text { Correlation }\end{array}$ & 1 & ,513 \\
\hline & Sig. (2-tailed) & &, 000 \\
\hline & $\mathrm{N}$ & 60 & 60 \\
\hline \multirow{3}{*}{ Komunikasi Efektif } & $\begin{array}{l}\text { Pearson } \\
\text { Correlation }\end{array}$ & ,513 & 1 \\
\hline & Sig. (2-tailed) & 000 & \\
\hline & $\mathrm{N}$ & 60 & 60 \\
\hline
\end{tabular}

Hasil analisis data di atas menunjukkan bahwa komunikasi efektif dapat meningkatkan literasi kesehatan mental masyarakat. Hal ini menunjukkan pentingnya komunikasi efektif dalam sebuah strategi komunikasi. Strategi komunikasi dalam Nine Steps of Strategic Public Relations yang dikemukakan oleh Smith (2005) akan digunakan untuk mengungkap strategi Into The Light Indonesia 
dalam meningkatkan literasi kesehatan mental di kalangan anak muda di Jabodetabek. Smith mengemukakan bahwa fase pertama yang perlu dilakukan adalah formative research, yakni menganalisis situasi, organisasi, dan publiknya. Untuk meningkatkan literasi kesehatan mental, perlu pemahaman akan situasi di Indonesia. Dalam wawancaranya, B. P. Siauw, pendiri Into The Light Indonesia, mengklaim bahwa situasi saat ini menunjukkan kurangnya pemahaman mengenai kesehatan mental masih terjadi tidak hanya di Indonesia, tetapi juga di seluruh dunia. Hal ini didukung oleh Patel et al. (2018) yang menyatakan bahwa lebih dari $80 \%$ orang dengan gangguan jiwa yang mencari penanganan. Dan meskipun mendapatkan penanganan, kualitasnya pun rendah.

Lebih lanjut B. P. Siauw mengemukakan bahwa terdapat perbedaan konteks literasi kesehatan mental di Indonesia dengan yang ada di negara-negara maju barat. Referensi literatur mengenai kesehatan mental yang ada saat ini masih didominasi oleh literatur-literatur barat, sehingga dibutuhkan sejumlah penyesuaianpenyesuaian informasi dalam literatur tersebut agar sesuai dengan konteks Indonesia,

"Karena misalnya ada aja nih masih orang yang udah punya akses internet tapi mereka ga tahu misalnya bahwa gangguan jiwa itu di-cover BPJS. Padahal itu bagian dari literasi kesehatan jiwa yang sesuai dengan konteks Indonesia. Konteks Indonesia kan itu di-cover ya berarti hal itu harusnya masuk tau dong karena itu bagian dari mencari bantuan profesional." (Wawancara B. P. Siauw, 28 April 2019)

Tidak hanya itu, stigma yang ada di negara-negara barat berbeda dengan stigma yang ada di Indonesia, terutama stigma yang tersebar mengenai gangguan jiwa atau bunuh diri. Di Indonesia, stigma yang muncul cenderung bersifat tanggung jawab kolektif. Sebagaimana dikemukakan oleh Gopalkrishnan (2018) bahwa keragaman budaya di dunia memiliki dampak signifikan pada banyak aspek kesehatan mental, mulai dari persepsi tentang kesehatan dan penyakit mental, perilaku pencarian bantuan, sikap masyarakat dan praktisi, dan sistem kesehatan mental. Namun, belakangan ini di Indonesia terjadi pergeseran stigma mengenai penyakit kejiwaan, sehingga stigma yang muncul cenderung lebih agamis dibandingkan dahulu. "Bilangnya dosa, bilangnya ga inget keluarga," ungkap B. P. Siauw (Wawancara, 28 April 2019). Terlebih pada kasus-kasus gangguan jiwa, B. P. Siauw menambahkan bahwa, "Spesifik di gangguan jiwa, mungkin mereka akan bilang itu karena adanya kiriman santet, makhluk halus" (Wawancara, 28 April 2019). Hal serupa diungkapkan oleh Lee et al. (2010) bahwa gangguan jiwa dianggap sebagai akibat roh, kutukan, atau karma buruk, yang dapat mengakibatkan perasaan tidak berdaya atau melakukan upaya pengobatan non-evidence-based. Sedangkan sebelumnya, pada tahun 1950-an, stigma yang muncul tentang penyakit kejiwaan di Indonesia antara lain sakit saraf, nekat, maupun sesuatu yang salah dalam kepala.

Selain membandingkan perbedaan stigma yang ada dulu dengan sekarang, B. P. Siauw mengungkapkan bahwa masyarakat di sekitar wilayah Jakarta dapat menikmati privilese dibandingkan dengan masyarakat di wilayah-wilayah lain. B. P. Siauw menceritakan mengenai pengalamannya saat mendapat kesempatan untuk berkunjung ke Palu dan Indramayu, di mana hampir tidak ada fasilitas bantuan profesional untuk kesehatan mental. Hal ini dikuatkan oleh pernyataan Himpunan 
Sarah Bryna Grace, Ade Gandha Kurnia Tandra, Mary: Komunikasi Efektif dalam Meningkatkan Literasi Kesehatan Mental

Psikologi Indonesia (HIMPSI) dalam Adam (2019), jumlah anggota profesional psikologi di Indonesia sebesar 11.500 orang. Sedangkan jumlah psikolog klinis yang terverifikasi menurut Ikatan Psikologi Klinis (IPK) Indonesia dalam Adam (2019), sebesar 1.143 orang. Tak hanya itu, Indonesia hanya memiliki 48 rumah sakit jiwa dan lokasinya masih terpusat di kota-kota besar di Pulau Jawa. Delapan provinsi tidak memiliki rumah sakit jiwa dan tiga provinsi tidak memiliki psikiater. Dengan tenaga psikiater yang sejumlah 600 hingga 800 orang, maka seorang psikiater harus melayani 300.000 hingga 400.000 jiwa.

Namun, B. P. Siauw mengakui bahwa di kalangan anak muda, literasi kesehatan mental sudah mengalami peningkatan, walaupun masih dianggap belum cukup. Hal ini dapat dilihat dari kehadiran komunitas-komunitas baru yang peduli akan kesehatan kejiwaan yang umumnya diprakarsai oleh orang-orang muda dengan awareness mengenai kesehatan mental. B. P. Siauw mengungkapkan,

"Komunitas-komunitas kesehatan jiwa yang baru muncul itu rata-rata orang muda. Yang mereka yang baru 18 tahun, mereka yang baru 20 tahun gitu, yang masih kuliah yang pengen, 'We need to do something about this,' gitu. Itu datang dari orang muda. Berbeda dengan naturnya komunitas-komunitas kesehatan jiwa di masa dulu. Misalnya ada beberapa komunitas yang dulunya tuh didirikan sama kelompok orang atau keluarga yang mengalami. Keluarganya mengalami gangguan jiwa juga. Jadi itu yang akhirnya membuat mereka bergerak.” (Wawancara B. P. Siauw, 28 April 2019)

Selain perlu menganalisis situasi literasi kesehatan mental di Indonesia pada saat ini, diperlukan adanya analisis situasi dalam segi kelemahan dan threats yang menjadi kendala dalam mencapai tujuan komunitas. B. P. Siauw mengungkapkan adanya kendala-kendala yang dihadapi oleh Into The Light Indonesia dalam upaya meningkatkan literasi kesehatan mental di Indonesia. Isu kesehatan mental belum menjadi topik yang sepopuler isu-isu kesehatan lain, seperti kanker ataupun HIV. Hal ini ditekankan juga oleh Jorm (2012) dalam hal pencegahan, banyak orang tahu tentang seks aman untuk mencegah HIV, tentang hubungan antara merokok dan berbagai penyakit, dan tentang kebiasaan makan yang sehat. Jorm mengungkapkan bahwa kontras dengan situasi kesehatan mental, banyak orang tidak tahu tentang apa yang dapat dilakukan dalam hal pencegahan, orang-orang sering menunda atau menghindari mencari pengobatan dan melihat tindakan yang direkomendasikan dengan kecurigaan, dan mereka tidak yakin bagaimana membantu orang lain dengan gangguan jiwa. Hal ini berdampak pada kurangnya dukungan masyarakat terhadap masalah ini. Kendala-kendala tersebut antara lain kendala finansial maupun penolakan masyarakat akan isu kesehatan mental.

B. P. Siauw mengungkapkan, kendala dalam segi finansial masih menjadi masalah utama dalam komunitas Into The Light Indonesia. Salah satu penyebabnya adalah status komunitas yang belum berbadan hukum. Sumber dana komunitas masih sangat terbatas, dan didominasi dari anggota komunitas sendiri serta donasi dari acara-acara yang digalang oleh organisasi lain. Kendala dalam segi finansial juga disebabkan oleh kurangnya kepedulian akan kesehatan mental apabila dibandingkan dengan isu-isu lain seperti kesehatan ibu dan anak, stunting, HIV, atau sejenisnya. Untuk menghadapi kendala finansial, diperlukan perencanaan yang matang untuk pemanfaatan dana secara maksimal. 
Selain itu, kendala dalam bentuk penolakan juga sudah beberapa kali terjadi. Seperti yang diungkapkan B. P. Siauw dalam wawancara, bentuk penolakan dapat terjadi baik secara perorangan maupun dilakukan oleh organisasi. Bentuk penolakan secara perseorangan dapat ditemukan dalam bentuk ekspresi jijik saat dibagikan brosur yang bertemakan kesehatan mental maupun bunuh diri. Bentuk penolakan lain yang dilakukan organisasi dapat ditemukan dalam bentuk conditional acceptance,

"Misalnya kayak, 'Oh ya udah gapapa kasih edukasi ya tentang kesehatan mental, tapi jangan ngomong bunuh diri.' So, halus gitu kan. Oke, bukan penolakan jadinya ya, conditional acceptance gitu. Karena takut. Masyarakat kita membicarakan kematian in general aja kan amit-amit gitu ya, apalagi ngomongin bunuh diri. Udah isinya dosa, segala macem gitu kan, jadi defense-defense itu pasti ada, kita ngalamin resistance." (Wawancara B. P. Siauw, 28 April 2019)

Dari tahap situational analysis di atas, dapat dilihat bahwa komunitas Into The Light Indonesia mampu mengidentifikasi kekuatan dan kelemahan serta kesempatan dan ancaman yang dihadapi oleh komunitas tersebut. Selanjutnya dalam Nine Steps of Strategic Public Relations menurut Smith (2017) fase-fase berikutnya setelah dilakukan analisis situasi adalah fase strategy, yakni menentukan tujuan dan objektif, menyusun strategi, dan menggunakan komunikasi efektif, dan fase tactics, yakni memilih taktik komunikasi serta mengimplementasikan strategic plan.

Dalam mewujudkan tujuan komunitasnya, Into The Light Indonesia sebagai organisasi nonprofit memiliki strategi online dan offline . Strategi online dilakukan melalui situs internet organisasi, Instagram, Twitter, Facebook, dan LINE. B. P. Siauw menekankan bahwa setiap informasi yang diunggah harus berasal dari jurnal-jurnal internasional dengan akreditasi yang jelas, karena diperlukan lebih dari sekadar niat baik untuk menyampaikan pesan-pesan mengenai kesehatan mental agar tepat sasaran. B. P. Siauw percaya bahwa evidence base dalam kesehatan mental sangat penting. Apabila menyebarkan informasi dengan poinpoin yang keliru artinya menyebarkan stigma ataupun mitos. Tidak hanya konten informasi yang perlu diperhatikan kualitasnya, tetapi juga cara penyampaiannya. B. P. Siauw menjelaskan bahwa Into The Light Indonesia sangat ketat dalam mengunggah infografis-infografisnya berdasarkan guideline yang berasal dari riset. TEAM Up (n.d.) menyediakan panduan untuk organisasi dalam penyampaian pesan mengenai isu bunuh diri dalam media sosial untuk mereduksi stigma, meningkatkan perilaku pencarian pertolongan, dan membantu mencegah bunuh diri. Salah satu poin pentingnya adalah penggunaan bahasa dan ilustrasi, seperti menghindari penggunaan istilah-istilah berstigma maupun label, menghindari penggunaan ilustrasi-ilustrasi yang stereotipikal, serta menghindari penjelasan-penjelasan mengenai metode-metode ataupun gambar-gambar kasus bunuh diri. Hal ini juga ditekankan oleh B. P. Siauw,

"Bukan terkait konten doang ya, how to deliver, cara kita men-deliver di Into The Light itu sangat dijaga SOP-nya. Infografis ga boleh ada visual method. Narasi, kalau memang ada yang dinarasikan metodenya atau misalnya kausal-kausalnya, itu dia ga boleh dramatisasi. Dia ga boleh nyebut metodenya dengan eksplisit." (Wawancara B. P. Siauw, 28 April 2019) 
Sarah Bryna Grace, Ade Gandha Kurnia Tandra, Mary: Komunikasi Efektif dalam Meningkatkan Literasi Kesehatan Mental

Namun, hal ini disanggah oleh $\mathrm{N}$. Wattimena yang menjelaskan bahwa, seperti halnya referensi literatur Barat yang perlu diadaptasi sesuai konteks lokal sebelum diterapkan di Indonesia, metode dalam penyampaian pesan pun perlu disesuaikan menurut konteks lokal. Sebagaimana diungkapkan oleh Jorm (2012) bahwa literasi kesehatan mental merepresentasikan konsep ilmu Barat yang mungkin bertentangan dengan kepercayaan tradisional rakyat setempat. Dalam hal ini, emotional appeal dianggap dapat meningkatkan interes masyarakat Indonesia. Wattimena mengungkapkan bahwa,

"Di Indonesia emang harus melas, kalo ga melas ga dapet ya. Jadi mungkin di sini harus juga mereka mengerti bahwa guideline ini ya mungkin, he cannot use 100 percent. Tidak semua guideline yang bagus, yang international credited, is good enough for Indonesia." (Wawancara N. Wattimena, 30 Juli 2019)

Selain strategi online, strategi offline dipakai oleh komunitas Into The Light Indonesia yang diwujudkan melalui edukasi, seminar singkat, workshop, dan juga pelatihan. Kegiatan-kegiatan ini umumnya dicetuskan oleh B. P. Siauw sendiri. Namun, tidak menutup kesempatan anggota-anggota lain untuk memberikan ideide segar sebagai kegiatan. Seperti contohnya kegiatan Creative Journaling for Mental Health yang berasal dari ide anggota komunitas Into The Light Indonesia. Dalam kegiatan-kegiatan offline, B. P. Siauw menegaskan bahwa narasumber yang menyampaikan materi harus memiliki nilai-nilai yang selaras dengan Into The Light Indonesia dan telah diseleksi oleh tim khusus dari Into The Light Indonesia. Selain itu, pencarian venue acara yang murah bahkan gratis dapat menjadi solusi untuk kendala finansial dari komunitas Into The Light Indonesia,

"Ya biasanya sih kita nentuin lokasi yang sebisa mungkin gratis. Yang penting gratis. Kita ga nyari market-nya dulu. Kita selalu optimis bahwa market-nya ada. Market research-nya itu berdasarkan topik, not by location. Jadi kalo topiknya memang menurut kita this is urgent, ini penting, dan ini bisa applicable, dan ada sesuatu yang bisa dibawa pulang sama peserta, ini meredakan satu masalah mereka, setidaknya gitu. Ya udah, tempat di mana aja boleh, ga masalah." (Wawancara B. P. Siauw, 28 April 2019)

Tidak sejalan dengan cara menentukan lokasi kegiatan oleh Into The Light Indonesia, N. Wattimena (Wawancara, 30 Juli 2019) menekankan bahwa salah satu hal penting dalam menentukan strategi komunikasi adalah melalui riset serta mapping yang jelas. Into The Light Indonesia perlu membuat mapping, misalnya dengan mencari daerah mana yang memiliki risiko bunuh diri tertinggi. Dengan mapping tersebut, Into The Light Indonesia bisa menentukan audience yang tepat.

Fase terakhir dalam Nine Steps of Strategic Public Relations menurut Smith (2017) adalah evaluative research, yakni mengevaluasi strategic plan yang telah dijalankan. B. P. Siauw menekankan bahwa selalu ada dskusi di setiap akhir kegiatan yang diadakan oleh Into The Light Indonesia. Namun N. Wattimena menambahkan bahwa sebuah evaluasi secara kuantitatif juga diperlukan untuk mengukur ketercapaiannya sebuah tujuan strategi komunikasi,

"Harus ada measurement, kalau menurut saya. Yang pertama kita jangan bilang kita meningkat, tapi how much. Kalau kita bicara strategi PR tuh yang terakhir evaluasi nah dari evaluasi itu kan kita akan bikin what next. ... Bikin strategi apa pun, kalau 
kita ga ada measurement, we don't know where we're going to." (Wawancara N. Wattimena, 30 Juli 2019)

Dengan demikian, measurement yang jelas perlu dibuat untuk bisa mengukur apa yang telah dicapai sehingga dapat menentukan tujuan berikutnya. Sebagaimana diungkapkan oleh Buhmann dan Likely (2018) bahwa evaluasi merupakan landasan dari keberhasilan strategi komunikasi.

\section{Simpulan}

Artikel ini merupakan hasil penelitian tentang komunikasi efektif yang dilakukan oleh komunitas Into The Light Indonesia terhadap tingkat literasi kesehatan mental anak muda di Jabodetabek. Peneliti menggunakan uji analisis independen $t$-test untuk menguji hipotesis komparatif dari tingkat literasi kesehatan mental partisipan dan nonpartisipan kegiatan komunitas Into The Light Indonesia, serta korelasi product moment dari Pearson untuk menguji hipotesis asosiatif dari hubungan antara tingkat literasi kesehatan mental dengan komunikasi efektif. Hasil uji analisis independen $t$-test mengungkapkan bahwa tidak ada perbedaan yang signifikan antara partisipan dan nonpartisipan dari kegiatan Into The Light Indonesia. Sedangkan hasil uji analisis korelasi product moment mengungkapkan bahwa terdapat hubungan kuat dan positif antara komunikasi efektif dalam penyampaian materi dengan tingkat literasi kesehatan mental.

Penelitian ini juga mengungkapkan strategi Into The Light Indonesia dalam meningkatkan literasi kesehatan mental yang dilakukan melalui kegiatan-kegiatan online dan offline. Kegiatan online meliputi situs internet organisasi serta media sosial seperti Instagram, Twitter, Facebook, dan LINE. Kegiatan offline dapat berbentuk edukasi, seminar singkat, workshop, dan juga pelatihan. Melalui kegiatan komunitas Into The Light Indonesia, partisipan kegiatan memiliki awareness mengenai literasi kesehatan mental dan memiliki interest untuk mencari informasi lebih banyak mengenai kesehatan mental.

Penelitian yang telah dilakukan menunjukkan bahwa pemahaman mengenai kesehatan mental masih terbatas. Untuk itu, diharapkan komunitas-komunitas yang peduli akan kesehatan mental dapat mengadakan kegiatan-kegiatan yang bisa dengan efektif memberi pemahaman tentang kesehatan kejiwaan. Dengan strategi komunikasi yang tepat, komunitas dapat menggapai masyarakat sekitarnya dan informasi dapat tersampaikan dengan optimal. Penggunaan media baru seperti internet bisa menjadi solusi untuk meningkatkan penetrasi literasi kesehatan mental pada orang muda. Solusi lainnya antara lain menambahkan pendidikan kesehatan mental ke dalam kurikulum institusi pendidikan formal. Hal ini dapat meningkatkan paparan mengenai kesehatan mental semenjak usia dini.

Berdasarkan hasil penelitian yang telah dilakukan, penulis memberikan saran terkait perlunya komunitas Into The Light Indonesia dalam melakukan kegiatan secara berkelanjutan untuk dapat meningkatkan pemahaman mengenai kesehatan mental secara optimal. Guna meningkatkan kualitas strategi komunikasi, Into The Light Indonesia juga perlu melakukan mapping secara komprehensif terlebih dahulu untuk dapat menentukan fokus kegiatan serta metode penyampaian pesan yang sesuai. Selain itu penulis juga menyarankan terkait pentingnya evaluasi 
Sarah Bryna Grace, Ade Gandha Kurnia Tandra, Mary: Komunikasi Efektif dalam Meningkatkan Literasi Kesehatan Mental

dan measurement, untuk dapat menghitung pencapaian dari strategi komunikasi yang telah dibuat, guna menentukan tujuan dan target-target berikutnya.

\section{Ucapan Terima Kasih}

Dengan terbitnya artikel ini, penulis mengucapkan terima kasih kepada London School of Public Relations Jakarta yang telah membantu dalam pelaksanaan penelitian ini. Selain itu, penulis juga mengucapkan terima kasih kepada pihak Into The Light Indonesia yang telah mengizinkan penulis untuk berpartisipasi untuk meneliti kegiatan komunitas.

\section{Daftar Pustaka}

Adam, A. (2019). Defisit psikiater dan psikolog, sebarannya terpusat di Jawa. https://tirto.id/defisit-psikiater-dan-psikolog-sebarannya-terpusat-di-jawadpk2

Afifah, K. A., Rachmah, N., \& Asyanti, S. (2016). Literasi kesehatan mental pada tenaga kesehatan [Universitas Muhammadiyah Surakarta]. http://eprints.ums.ac.id/48098/

Astuti, S. D., Putri, I. P., \& Ali, D. S. F. (2016). Strategi komunikasi program Internet Sehat dan Aman Kementerian Komunikasi dan Informatika Republik Indonesia (Studi kasus evaluasi program Incakap tahun 2015). Jurnal Komunikasi, 8(1), 25-35. https://journal.untar.ac.id/index.php/komunikasi/article/view/47

Badan Penelitian dan Pengembangan Kesehatan. (2013). Riset kesehatan dasar 2013. Badan Penelitian dan Pengembangan Kesehatan Kementerian Kesehatan RI.

Badan Penelitian dan Pengembangan Kesehatan. (2018). Hasil utama riskesdas 2018. Badan Penelitian dan Pengembangan Kesehatan Kementerian Kesehatan RI.

Bharadwaj, P., Pai, M. M., \& Suziedelyte, A. (2017). Mental health stigma. Economics Letters, 159, 57-60. https://doi.org/10.1016/j.econlet.2017.06.028

Bird, P., Omar, M., Doku, V., Lund, C., Nsereko, J. R., \& Mwanza, J. (2011). Increasing the priority of mental health in Africa: Findings from qualitative research in Ghana, South Africa, Uganda and Zambia. Health Policy and Planning, 26(5), 357-365. https://doi.org/10.1093/heapol/czq078

Buhmann, A., \& Likely, F. (2018). Evaluation and Measurement. In R. L. Heath \& W. Johansen (Ed.), The international encyclopedia of strategic communication (hal. 1-12). https://doi.org/10.1002/9781119010722.iesc0103

Crawford, E. C., \& Okigbo, C. C. (2014). Strategic communication campaigns. In C. C. Okigbo (Ed.), Strategic urban health communication (hal. 11-23). Springer. https://dl.uswr.ac.ir/bitstream/Hannan/131998/1/9781461493341.pdf 
Creswell, J. W. (2014). Research design: Qualitative, quantitative, and mixed methods approaches (4th ed.). SAGE Publications.

Di provinsi mana banyak orang bunuh diri? (2016). https://databoks.katadata.co.id/datapublish/2016/12/22/jawa-tengahprovinsi-dengan-kasus-bunuh-diri-terbanyak-di-Indonesia

Ennis, G., Happell, B., Broadbent, M., \& Reid-Searl, K. (2013). The importance of communication for clinical leaders in mental health nursing: The perspective of nurses working in mental health. Issues in Mental Health Nursing, 34(11), 814-819. https://doi.org/10.3109/01612840.2013.829539

Fallowfield, L., \& Jenkins, V. (1999). Effective communication skills are the key to good cancer care. European Journal of Cancer, 35(11), 1592-1597. https://doi.org/10.1016/S0959-8049(99)00212-9

Fanada, D. (2017). Daftar komunitas yang peduli kesehatan jiwa. https://www.rappler.com/indonesia/ayo-indonesia/177608-daftarkomunitas-peduli-kesehatan-jiwa

Gopalkrishnan, N. (2018). Cultural diversity and mental health: Considerations for policy and practice. Frontiers in Public Health, 6. https://doi.org/10.3389/fpubh.2018.00179

Gunter, B. (2002). The quantitative research process. In K. B. Jensen (Ed.), A handbook of media and communication research: Qualitative and quantitative methodologies (hal. 209-234). Routledge.

Hair, J. F., Gabriel, M. L. D. S., da Silva, D., \& Braga Junior, S. (2019). Development and validation of attitudes measurement scales: Fundamental and practical aspects. RAUSP Management Journal, 54(4), 490-507. https://doi.org/10.1108/RAUSP-05-2019-0098

Hallahan, K., Holtzhausen, D., van Ruler, B., Verčič, D., \& Sriramesh, K. (2007). Defining strategic communication. International Journal of Strategic Communication, 1(1), 3-35. https://doi.org/10.1080/15531180701285244

Into The Light Indonesia. (n.d.). Profil. https://www.intothelightid.org/ tentangkami/profil/

Jorm, A. F. (2000). Mental health literacy: Public knowledge and beliefs about mental disorders. The British Journal of Psychiatry, 177(5), 396-401. https://doi.org/10.1192/bjp.177.5.396

Jorm, A. F. (2012). Mental health literacy: Empowering the community to take action for better mental health. American Psychologist, 67(3), 231-243. https://doi.org/10.1037/a0025957

Kahn, A. (n.d.). Suicide and suicidal behavior. https://www.healthline.com/ health/suicide-and-suicidal-behavior

Kelly, C. M., Jorm, A. F., \& Wright, A. (2007). Improving mental health literacy as a strategy to facilitate early intervention for mental disorders. Medical Journal of Australia, 187, 26-30. https://doi.org/10.5694/j.13265377.2007.tb01332.x

Kutcher, S., Wei, Y., \& Coniglio, C. (2016). Mental health literacy: Past, present, and future. The Canadian Journal of Psychiatry, 61(3), 154-158. https://doi.org/10.1177/0706743715616609 
Sarah Bryna Grace, Ade Gandha Kurnia Tandra, Mary: Komunikasi Efektif dalam Meningkatkan Literasi Kesehatan Mental

Larson, C. U. (2010). Persuasion: Reception and responsibility (12th ed.). Wadsworth.

Lee, H. Y., Lytle, K., Yang, P. N., \& Lum, T. (2010). Mental health literacy in Hmong and Cambodian elderly refugees: A barrier to understanding, recognizing, and responding to depression. The International Journal of Aging and Human Development, 71(4), 323-344. https://doi.org/10.2190/AG.71.4.d

Livingston, J. D., Tugwell, A., Korf-Uzan, K., Cianfrone, M., \& Coniglio, C. (2013). Evaluation of a campaign to improve awareness and attitudes of young people towards mental health issues. Social Psychiatry and Psychiatric Epidemiology, 48(6), 965-973. https://doi.org/10.1007/s00127012-0617-3

Makkasau, K. (2013). Penggunaan metode analytic hierarchy process (AHP) dalam penentuan prioritas program kesehatan (Studi kasus program promosi kesehatan). J@ti Undip: Jurnal Teknik Industri, 7(2), 105-112. https://doi.org/10.12777/jati.7.2.105-112

Marchira, C. R. (2011). Integrasi kesehatan jiwa pada pelayanan primer di Indonesia: Sebuah tantangan di masa sekarang. Jurnal Manajemen Pelayanan Kesehatan, 14(3), 120-126. https://jurnal.ugm.ac.id/jmpk/article/view/2574/2306

Matta, A. (2016). Kesehatan mental di Indonesia hari ini. https://tirto.id/kesehatanmental-di-indonesia-hari-ini-b9tw

Mawarpury, M., Sari, K., \& Safrina, L. (2017). Layanan kesehatan mental di puskesmas: Apakah dibutuhkan? Insight: Jurnal Pemikiran dan Penelitian Psikologi, 13(1), 1-10. http://jurnal.unmuhjember.ac.id/index.php/INSIGHT/article/view/578

O'Connor, M., \& Casey, L. (2015). The Mental Health Literacy Scale (MHLS): A new scale-based measure of mental health literacy. Psychiatry Research, 229(1-2), 511-516. https://doi.org/10.1016/j.psychres.2015.05.064

Patel, V., Saxena, S., Lund, C., Thornicroft, G., Baingana, F., Bolton, P., Chisholm, D., Collins, P. Y., Cooper, J. L., Eaton, J., Herrman, H., Herzallah, M. M., Huang, Y., Jordans, M. J. D., Kleinman, A., Medina-Mora, M. E., Morgan, E., Niaz, U., Omigbodun, O., ... Unützer, J. (2018). The Lancet Commission on global mental health and sustainable development. The Lancet Commissions, 392(10157), 1553-1598. https://doi.org/10.1016/S0140-6736(18)31612-X

Smith, R. D. (2017). Strategic planning for public relations (5th ed.). Routledge.

Sugiyono. (2015). Metode penelitian pendidikan (Pendekatan kuantitatif, kualitatif, dan $R \& D)$ (22nd ed.). Alfabeta.

Sujarweni, V. W. (2016). SPSS untuk penelitian. Pustaka Baru.

TEAM Up. (n.d.). Social media guidelines for mental health promotion and suicide prevention. http://www.eiconline.org/teamup/wp-content/files/ teamupmental-health-social-media-guidelines.pdf

Thara, R., \& Patel, V. (2010). Role of non-governmental organizations in mental health in India. Indian Journal of Psychiatry, 52(7), 389-395. https://doi.org/10.4103/0019-5545.69276 
Tunggala, S., \& Saadjad, K. A. (2019). Strategi komunikasi pada Dinas Kebudayaan dan Pariwisata dalam mempromosikan objek wisata Kabupaten Banggai. Jurnal Komunikasi, 11(2), 197-212. https://doi.org/10.24912/jk.v11i2.2714

World Health Organization. (n.d.). Mental health included in the UN Sustainable Development Goals. https://www.who.int/ mental_health/SDGs/en/ 